\title{
Estruturas de governança no interior do estado de São Paulo: participação truncada e assimetrias de informação
}

\author{
Wilson Bento Figueiredo Filho \\ Academia da Força Aérea - Pirassununga - São Paulo - Brasil
}

\begin{abstract}
Resumo
Este artigo propõe um modelo, formado pelos conceitos de ator e instituições, para descrever o funcionamento de algumas estruturas de governança no interior do estado de São Paulo, apoiado nos resultados de uma pesquisa que buscou problematizar sua importância para o desenvolvimento sustentável regional. Por suposto, a função primária destas estruturas é a cooperação. No entanto, a coleta de dados secundários e o trabalho de campo indicaram sua fragilidade, evidenciada pela baixa participação e pelas assimetrias de informação. Uma possível explicação é proposta a partir da matriz institucional brasileira que, baseada nos valores da família patriarcal, legitima comportamentos oligárquicos e patrimonialistas que dificultam a cooperação. Mesmo assim, podem ser descritas como uma tentativa de afastamento daqueles comportamentos ao iniciar uma lenta mudança institucional.
\end{abstract}

Palavras-Chave: Jogo. Atores. Instituições. Patrimonialismo. Governança.

Governance structures in the state of São Paulo: low participation and information asymmetries

\begin{abstract}
This article proposes a model, shaped by concepts of actors and institutions, to describe the operation of some structures of governance in State of São Paulo, based on results of a research that sought to discuss its importance for sustainable regional development. Supposedly, the primary function of these structures is cooperation. However, secondary data and field reserach indicated its fragility, evidenced by low participation and asymmetric information. A possible explanation is proposed from Brazilian institutional framework, based on the values of the patriarchal family, legitimizes oligarchic and patrimonial behaviors that hinder cooperation. Even so, they can be described as attempt to stand back from those behaviors to start a slow institutional change.
\end{abstract}

Keywords: Game. Actors. Institutions. Patrimonialism. Governance. 


\section{Estructuras de gobernanza en el interior del estado de São Paulo: participación truncada y asimetrías de información}

\section{Resumen}

Este artículo propone un modelo, formado por los conceptos de actor e instituciones, para describir el funcionamiento de algunas estructuras de gobernanza en el interior del estado de São Paulo, apoyado en los resultados de una investigación que buscó problematizar su importancia para el desarrollo sostenible regional. Por supuesto, la función primaria de estas estructuras es la cooperación. Sin embargo, la recolección de datos secundarios y el trabajo de campo indicaron su fragilidad, evidenciada por la baja participación y por las asimetrías de información. Una posible explicación es propuesta a partir de la matriz institucional brasileña que, basada en los valores de la familia patriarcal, legitima comportamientos oligárquicos y patrimonialistas que dificultan la cooperación. Aún así, pueden ser descritas como un intento de alejamiento de aquellos comportamientos al iniciar un lento cambio institucional.

Palabras-Clave: Juego. Actores. Instituciones. Patrimonialismo. Gobernanza.

\section{Introdução}

O grupo de pesquisa "Estruturas de governança e desenvolvimento territorial" desenvolveu o projeto de pesquisa "As Modalidades de Governança Territorial no Estado de São Paulo: territórios, políticas públicas e desenvolvimento". ${ }^{1}$ Seu objetivo principal foi problematizar a importância das estruturas de governança para as estratégias de desenvolvimento territorial sustentável no interior do estado de São Paulo.

Supondo que as relações entre atores dentro das estruturas de governança podem ser descritas como um jogo regulado por regras legítimas, a hipótese inicial sobre seu funcionamento era de que elas promoviam a cooperação através do encaminhamento dos conflitos, o que resultaria em acordos que reforçariam a densidade das relações entre atores e contribuiriam para um desenvolvimento territorial sustentável mais adequado às aspirações de determinada sociedade. Neste sentido, reduziriam a incerteza e as assimetrias de informação, provendo alguma ordem para os atores pensar e agir.

Entretanto, a coleta de dados secundários e o trabalho de campo indicaram que as estruturas de governança apresentavam pequena participação e assimetrias de informação, evidenciando a fragilidade da cooperação. Este artigo propõe uma discussão deste resultado geral a partir da matriz institucional brasileira que, baseada nos valores da família patriarcal, legitima alguns comportamentos oligárquicos e patrimonialistas que dificultam o funcionamento das estruturas de governança justamente no que elas têm de mais nobre: o trabalho em grupo e a construção de acordos. Mesmo assim, podem ser descritas como uma tentativa inicial de afastamento daqueles comportamentos ao iniciar uma mudança institucional que é lenta e demorada.

Para expor com mais detalhes a hipótese inicial e os resultados encontrados, este artigo está organizado em sete seções, contando com esta introdução. A

\footnotetext{
${ }^{1}$ Projeto de pesquisa desenvolvido sob a coordenação do Prof. Dr. Élson L. Pires do Departamento de Planejamento Regional - DEPLAN - da UNESP, campus Rio Claro e financiado pela FAPESP (processo $11 / 50837-9)$.
} 
segunda seção descreve de maneira geral a metodologia da pesquisa desenvolvida. $\mathrm{Na}$ terceira seção, os conceitos de ator e instituição são usados para montar um modelo, ou seja, um sistema simplificado da realidade que pode ser descrito como um jogo. Utilizando este modelo, a quarta seção expõe a hipótese inicial. A quinta seção mostra alguns resultados que evidenciam a baixa participação e as assimetrias de informação e fornecem indícios de que as estruturas de governança não promovem a cooperação ao encaminhar conflitos. Na sexta seção, é sugerida uma possível explicação para a fragilidade da cooperação baseada na matriz institucional brasileira que legitima comportamentos que dificultam a cooperação e a participação. Mesmo assim, as estruturas de governança podem ser descritas como tentativas iniciais para aumentar a cooperação via participação. Por fim, na sétima seção, há algumas considerações gerais sobre os resultados encontrados.

\title{
2 Breve descrição da metodologia da pesquisa desenvolvida²
}

O objetivo da pesquisa foi identificar, caracterizar e problematizar a importância das estruturas de governança territorial como elemento central necessário aos estudos e estratégias de planejamento do desenvolvimento sustentável no estado de São Paulo, entre 2003 e 2010 (PIRES et al., 2011)³.

\begin{abstract}
Este período é bastante significativo para compreender a história recente dos fenômenos em questão, principalmente levando em consideração a consolidação da abertura econômica do país, a descentralização do aparelho de estado e a criação de mecanismos mais democráticos de decisão e execução (PIRES et al., 2011, p. 13).
\end{abstract}

A escolha das estruturas que seriam estudadas obedeceu a três critérios. $\mathrm{O}$ primeiro foi identificar quais tipos de estrutruras de governança funcionavam no interior do estado de São Paulo através de informações disponíveis nos endereços eletrônicos das Secretarias Estaduais do Desenvolvimento e da Agricultura e Abastecimento. O grupo encontrou quatro tipos: Arranjos Produtivos Locais, Câmaras Setoriais, Circuitos Setoriais e Comitês de Bacia Hidrográfica.

No entanto, algumas estruturas não funcionavam de fato. Por exemplo, o único Comitê de Bacia Hidrográfica em funcionamento é o PCJ (Comitê das Bacias dos Rios Piracicaba, Capivari e Jundiaí). Por este motivo, o segundo critério diz respeito à disponibilidade de informações catalogadas em documentos e atas para avaliar os níveis de representatividade, cooperação e coordenação. Finalmente, o terceiro critério foi dado pelos recursos financeiros previstos para diárias e transporte para o trabalho de campo (PIRES et al., 2012).

O quadro 1 mostra as estruturas de governança que foram escolhidas com base nos três critérios.

\footnotetext{
${ }^{2}$ Esta descrição dos procedimentos metodológicos que nortearam a pesquisa está presente em outro artigo sobre os resultados da pesquisa. Ver Figueiredo Filho (2015).

3 Para economizar espaço e tornar a leitura mais fácil, utilizo a referência Pires et al. ao invés listar todos os autores envolvidos na feitura do projeto de pesquisa e dos relatórios de pesquisa citados neste artigo. Os nomes de todos os autores citados estão nas referências bibliográficas.
} 
Quadro 1. Estruturas de governança escolhidas

\begin{tabular}{|c|c|c|}
\hline Estrutura de governança & $\begin{array}{l}\text { Quantidade de municípios } \\
\text { abrangidos }\end{array}$ & $\begin{array}{l}\text { Municípios de } \\
\text { referência }\end{array}$ \\
\hline \multicolumn{3}{|l|}{ Comitê de bacia } \\
\hline PCJ & 66 & Americana \\
\hline \multicolumn{3}{|l|}{ Câmaras setoriais } \\
\hline Frutas & 16 & Jundiaí \\
\hline Turismo rural & 19 & Itu \\
\hline Uva e vinho & 11 & São Roque \\
\hline \multicolumn{3}{|l|}{ Circuitos turísticos } \\
\hline Águas & 8 & Serra Negra \\
\hline Frutas & 10 & Jundiaí \\
\hline \multicolumn{3}{|l|}{ Arranjos produtivos locais } \\
\hline Têxtil e confecções & 5 & Americana \\
\hline Confecções infantis & 2 & Tietê \\
\hline $\begin{array}{l}\text { Bordados de cama, mesa e } \\
\text { banho }\end{array}$ & 1 & Ibitinga \\
\hline Calçados infantis & 11 & Birigui \\
\hline Calçados femininos & 10 & Jaú \\
\hline Cadeia do etanol & 10 & Piracicaba \\
\hline Metal mecânico & 1 & Sertãozinho \\
\hline Médico hospitalar & 1 & Ribeirão Preto \\
\hline Aeroespacial e defesa & 4 & S.J. dos Campos \\
\hline Semi joias & 1 & Limeira \\
\hline Cerâmica artística & 1 & Porto Ferreira \\
\hline
\end{tabular}

Fonte: Pires et al. (2011)

Feita a escolha das estruturas que seriam estudadas, o grupo começou a coleta dos dados secundários para conhecer as dinâmicas econômica, política e social dos municípios que participam das estruturas listadas pela tabela 1.

O pressuposto geral que embasou a coleta de dados foi a descentralização que, a partir da Constituição de 1988 e da abertura comercial nos anos 1990, tornou estados e municípios responsáveis, ao menos em parte, pelo seu próprio desenvolvimento e gerou novas dinâmicas e ordenações sociais que, por sua vez, levaram a novas composições regionais marcadas pela diversidade de interesses (PIRES et al., 2011).

Para caracterizar a dinâmica econômica, o grupo utilizou dados do Instituto Brasileiro de Geografia e Estatística (IBGE), Instituto de Economia Agrícola (IEA), RAIS (Relação Anual de Informações Sociais) e Fundação Sistema Estadual de Análise de Dados (Fundação SEADE) para conhecer população, PIB, PIB per capita, Valor Adicionado, trabalhadores ocupados, número e tamanho dos estabelecimentos e exportações e importações. Estas informações forneceram indícios sobre o processo de desconcentração espacial da produção, a evolução do perfil do emprego, as mudanças salariais, o padrão de concorrência entre as empresas e o grau de abertura comercial dos municípios (PIRES et al., 2011).

As dinâmicas políticas e sociais existentes no âmbito das estruturas de governança foram caracterizadas a partir de três critérios. O primeiro deles foi estabelecer o perfil e evolução das organizações associativas de naturezas diversas 
para captar indícios dos mecanismos de participação (dados obtidos na RAIS). O segundo critério foi estabelecer o perfil dos partidos políticos presentes no poder executivo municipal para identificar as eventuais influências dos programas partidários sobre o funcionamento das estruturas (dados obtidos no Tribunal Superior Eleitoral - TSE). O terceiro critério é representado pelas despesas municipais realizadas por função (econômica, política e gastos sociais) para evidenciar o papel dos municípios no financiamento do desenvolvimento municipal, a partir dos dados do IBGE (PIRES et al., 2011).

O grupo optou por entrevistas e pela participação nas reuniões (metodologia de grupos focais) para enfrentar o desafio metodológico de identificar quais atores participavam das estruturas, quais eram os hegemônicos e os processos de decisão (PIRES et al., 2011). Este trabalho está ligado a este desafio na medida em que propõe um modelo, que pode ser descrito como um jogo, formado pelos conceitos de atores e instituições para descrever o funcionamento das estruturas de governança e interpretar os resultados encontrados.

\title{
3 Metodologia do modelo proposto: jogo, atores e instituições ${ }^{4}$
}

Os modelos aplicados às Ciências Sociais representam de maneira simplificada um conjunto de relações sociais através de um conjunto coerente de conceitos e das relações entre eles para melhor descrever aspectos da realidade e para explicar e prever acontecimentos (SILVA, 1987)

De Bruyne; Herman; Schoutheete (1997) propõem uma metodologia baseada na articulação de quatro polos: o epistemológico, o teórico, o morfológico e o técnico. A construção de modelos situa-se no polo morfológico que tem por finalidade a elaboração dos objetos científicos. É nele que os conceitos se articulam em uma arquitetônica mais ou menos rigorosamente construída.

\begin{abstract}
Este polo representa o plano de organização dos fenômenos, os modos de articulação da expressão teórica objetivada da problemática da pesquisa. Ao mesmo tempo, ele é o quadro operatório, prático, da representação, da elaboração, da estruturação dos objetos científicos (DE BRUYNE; HERMAN; SCHOUTHEETE, 1997, p. 159).
\end{abstract}

Estes por sua vez não são um "ser" ou uma "coisa" tangível. "O objeto científico é produzido como um efeito das regras ou feixes de relações que os pesquisadores manipulam" (DE BRUYNE; HERMAN; SCHOUTHEETE, 1997, p. 49).

O modelo proposto para construir o objeto científico é formado por dois conceitos, atores e instituições, e as relações entre eles podem ser descritas como um jogo. Os atores são definidos como grupo de indivíduos ligados por interesses e valores comuns que se relacionam com outros grupos com vistas ao seu próprio objetivo. São estratégicos, ou seja, adotam comportamentos cooperativos ou competitivos conforme a situação em que se encontrem (FIGUEIREDO FILHO, 2015).

Para Matus (1996) só é ator o grupo que controla recursos cognitivos, econômicos, políticos ou gerenciais, pois estes facilitam a conquista dos objetivos.

\footnotetext{
${ }^{4} \mathrm{~A}$ ideia geral desta seção começou a ser desenvolvida em outros artigos (Ver Figueiredo Filho, 2012 e 2015).

5 Verbete "modelo". Dicionário de Ciências, p. 773.
} 
Por este motivo, além dos objetivos, procuram acumular tais recursos cooperando ou competindo com os demais atores. Neste sentido, North (1993) afirma que as motivações dos atores são complexas e não são estáveis.

O resultado é a incerteza como característica básica do jogo. Para minimizá-la, os atores buscam informações sobre a situação na qual se encontram e sobre a conduta dos demais atores. No entanto, as informações não permitem melhorar a decisão porque os atores as processam de maneira subjetiva e incompleta (NORTH, 1993). O que, de acordo com Lessa (1998), leva a um paradoxo: conforme aumenta a massa de informação, mais informações são necessárias.

As instituições fornecem parâmetros através de um conjunto de regras, formais e informais, que reduzem a incerteza e as assimetrias de informação, dando alguma ordem às interações entre atores ao fornecer esquemas legítimos de referência para que eles possam pensar, agir e estimar as possíveis respostas dos demais atores às suas ações (FIGUEIREDO FILHO, 2015).

O que distingue as instituições como estabilizadores das relações entre atores é a legitimidade, isto é, a adesão espontânea a elas (BUCKLEY, 1971). Neste mesmo sentido, Douglas (1998) sustenta que as instituições são convenções que surgem a partir de interesses comuns que demandam coordenação. Podem ser violadas ou ignoradas na mesma medida em que perdem legitimidade.

Hall e Taylor (2003), referindo-se ao institucionalismo sociológico, dizem que as instituições fornecem modelos legítimos para interpretar a realidade e o comportamento dos atores e estabelecem as escolhas possíveis em determinado contexto. Também influenciam os cálculos estratégicos e as preferências dos atores ao conciliar a lógica da convivência social e a lógica instrumental.

Assim, os atores, a partir de diferentes interesses e objetivos, cooperam e competem formatados pelas instituições. As relações entre atores e entre estes e as instituições formam um modelo que pode ser descrito como um jogo. A utilidade do modelo vem da sua capacidade de explicar e prever alguns fenômenos postos pela realidade. Neste sentido, cabe destacar brevemente três autores que utilizam o jogo para interpretar a realidade.

Pozzi (1983), por exemplo, propõe estudar a sociedade prussiana através dos jogos de guerra. No entanto, ele generaliza que os jogos, esportivos ou de guerra, captam com clareza as características básicas de dada sociedade. Como exemplo, cita o caso dos jogos de guerra prussianos que continham um forte viés matemático. Com o início das revoluções burguesas, os jogos de guerra passam a retratrar as incertezas das novas relações sociais através do dado.

Aaron (1986) utiliza o futebol para descrever as relações entre países. Exceto pelas regras aceitas por todos e o objetivo comum a todos, as relações entre paises são caracterizadas pela incerteza decorrente da interação entre jogadores, técnicos, árbritos e torcida. 
Matus (1996), preocupado com a eficácia da ação governamental, descreve as relações entre atores - governos, empresas, sindicatos, universidades, organizações não governamentais, etc. - como um jogo, no qual competem e cooperam para atingir seus objetivos através do acúmulo de recursos cognitivos, econômicos, políticos e gerenciais para neutralizar adversários, atrair aliados e chegar o mais perto possível do objetivo desejado.

\section{A hipótese inicial: estruturas de governança como um jogo}

O modelo proposto parte de dois pressupostos. O primeiro é de que o êxito do desenvolvimento territorial está associado à ampliação da participação de governos, empresários, organizações associativas de naturezas diversas, universidades, sindicatos, etc.; à existência e funcionamento de mecanismos de regulação desta participação ampliada; e à mobilização de interesses dos vários atores em torno de um projeto econômico e social (PIRES et al., 2012).

O segundo é que nenhum ator em âmbito regional tem os recursos econômicos, políticos, cognitivos e gerenciais para enfrentar sozinho os problemas postos pela busca do desenvolvimento sustentável regional. São obrigados a cooperar. De acordo com este raciocínio, as estruturas de governança contribuiriam para o desenvolvimento territorial sustentável regional ao estimular a participação, levando mais atores a cooperar e competir (FIGUEIREDO FILHO, 2012).

De fato, a busca pelo desenvolvimento sustentável é tarefa complexa que envolve uma grande variedade de interesses mesclada às exigências postas pela economia, ecologia e equidade. De acordo com Beck (2003), os processos de desenvolvimento atuais são caracterizados pela consciência do risco, isto é, a dificuldade crescente de controlar suas consequências espaciais, temporais e sociais. Quem pagará pela poluição? Pelo crescimento urbano desordenado? Pelo desemprego causado pelo avanço tecnológico? Por outro lado, como gerar emprego e renda? As respostas variam conforme os interesses dos atores. Aqueles preocupados com a geração de emprego e renda terão respostas diferentes daqueles preocupados com o meio ambiente. Justificam suas posições a partir de argumentos institucionais, técnicos e econômicos.

De acordo com Douglas (1998), participam de um diálogo de surdos. Cada ator justifica seus interesses e conhecimentos baseado em comportamentos - sectários, individualistas, hierárquicos, cooperativos, etc. - legitimados pelas instituições. Olham os problemas postos pela busca do desenvolvimento sustentável e o enfrentamento das suas consequências a partir de diferentes lógicas e critérios.

Em âmbito regional, a mesma situação se repete. Os atores mobilizam seus recursos para chegarem o mais perto possível da sua visão do processo de desenvolvimento sustentável e de seus objetivos, recorrendo às instituições e aos seus argumentos técnicos e econômicos para justificar suas ações. Dado os pressupostos do modelo, os atores regionais demandam mecanismos que facilitem a cooperação para ordenar a participação e encaminhar os conflitos decorrentes da diversidade de interesses. 
Os comitês de bacia hidrográfica, os circuitos turísticos, os arranjos produtivos locais e as câmaras setoriais, as estruturas de governança identificadas pelo grupo de pesquisa, representam alguns destes mecanismos. Eles permitem aos atores cooperar e competir, reduzindo a incerteza e a assimetria de informações ao fornecer um esquema legítimo de referência para pensar e agir. "As decisões e ações dos atores dentro dessas estruturas conformam um território caracterizado pelas relações de poder entre eles e que podem ser descritas como um jogo" (FIGUEIREDO FILHO, 2012, p. 143).

As estruturas de governança deveriam reduzir os riscos e a "surdez" envolvidos no jogo, incentivando comportamentos cooperativos que facilitariam a construção de acordos. Os atores teriam clareza dos interesses envolvidos em cada acordo e na medida em que tais acordos fossem cumpridos haveria um aumento de legitimidade que facilitaria a construção de novos acordos e incentivaria a participação de novos atores. Neste caso, as estruturas de governança podem ser descritas como inovações institucionais que facilitam a cooperação ao estimular a participação e reduzir as assimetrias de informação. Fornecem alguns parâmetros para conformar e estabilizar as expectativas dos atores interessados pela busca do desenvolvimento sustentável regional e abrir caminho para a cooperação a partir do encaminhamento dos conflitos.

Entretanto, os resultados indicam dificuldades na cooperação. A próxima seção evidencia estes resultados com base em dez princípios básicos da boa governança propostos por todos os pesquisadores. Estes princípios fornecem indícios da participação truncada e da existência de assimetrias de informação.

\section{Baixa participação e informação truncada}

O grupo de pesquisa chegou a sete resultados que, de maneira geral, se aplicam às estruturas de governança estudadas: i) a participação das secretarias de governo e das universidades é pontual. Fatecs, FIESP, SEBRAE e prefeituras municipais são os participantes mais comuns; ii) as ações dos partidos que comandam as prefeituras dos municípios participantes das várias modalidades de governança não se diferenciam entre si; iii) a maioria das estruturas de governança não têm agenda, mecanismos de rodízio de poder e decisão; iv) sobreposição de governanças: um único município pode participar de várias estruturas; v) multiplicidade de organizações dos governos federal, estadual e municipais que não se articulam e não se comunicam entre si com efetividade; vi) falhas de comunicação e coordenação de ações que elevam os custos operacionais e reduzem a transparência; vii) pequena organização social e política para desenvolver e implantar projetos de desenvolvimento sustentável (PIRES et al., 2013).

Além destes resultados, o grupo de pesquisa classificou as estruturas de governança estudadas com base em dez princípíos qualitativos, conforme mostra o quadro 2 logo abaixo, que

[...] foram selecionados com base na literatura, e sintetizam os princípios básicos que alteram o funcionamento da governança e que, portanto, permitem medir os objetivos por elas previstos. A análise dos aspectos qualitativos do caráter dos princípios da governança deve contribuir na interpretação do papel que cumpre cada um dos atores no desempenho 
positivo/negativo da governança. A análise foi realizada a partir da percepção crítica dos pesquisadores na análise de cada elemento observado (PIRES et al., 2013, p. 8). Each project is an organized sequence of human actions aimed at achieving the assumed result. Characteristic features of the project are: high degree of complexity, uniqueness, specific implementation time. Projects are accompanied by various types of risks, and their implementation requires the involvement of specific resources: human, material, financial and specialist knowledge. The project can also be described as a new, atypical project that differs from routine activities, and at the same time as a coherent and coordinated operation, with clearly defined objectives, aimed at carrying out an indivisible task (PL-SK, 20072013). 

Quadro 2. Avaliação dos princípios da Governança territorial no Estado de São Paulo

\begin{tabular}{|c|c|c|c|c|c|c|c|c|c|c|c|}
\hline & & Foco & Mecanismos & Transparência & Participação & Representatividade & Accountability & Coerência & Confiança & Subsidiariedade & Autonomia \\
\hline \multirow{11}{*}{$\begin{array}{c}\text { Arranjos } \\
\text { Produtivos } \\
\text { Locais }\end{array}$} & Têxtil e Confecções & Baixa & baixa & baixa & Baixa & baixa & baixa & baixa & baixa & baixa & baixa \\
\hline & Confecções Infantis & Baixa & baixa & baixa & Baixa & baixa & baixa & baixa & baixa & baixa & baixa \\
\hline & $\begin{array}{l}\text { Bordados de cama, } \\
\text { mesa e banho }\end{array}$ & Baixa & baixa & baixa & Baixa & baixa & baixa & baixa & baixa & baixa & baixa \\
\hline & Calçados Infantis & Baixa & baixa & baixa & Baixa & baixa & baixa & baixa & baixa & baixa & baixa \\
\hline & Calçados Femininos & Baixa & baixa & baixa & Baixa & baixa & baixa & baixa & baixa & baixa & baixa \\
\hline & Cerâmica Artística & Baixa & baixa & baixa & Baixa & baixa & baixa & baixa & baixa & baixa & baixa \\
\hline & Cadeia do Etanol & Baixa & baixa & baixa & Baixa & baixa & baixa & baixa & baixa & baixa & baixa \\
\hline & Metal-mecânico & Baixa & baixa & baixa & Baixa & baixa & baixa & baixa & baixa & baixa & baixa \\
\hline & $\begin{array}{l}\text { Equipamento Médico- } \\
\text { Hosp. e Odontológico }\end{array}$ & média-alta & alta & média-baixa & Média & média & média-baixa & média & média & média & baixa \\
\hline & $\begin{array}{l}\text { Aeroespacial e } \\
\text { Defesa }\end{array}$ & Alta & alta & média-alta & Baixa & média-baixa & média & média-alta & média-alta & baixa & média-alta \\
\hline & $\begin{array}{l}\text { Semi-jóias e } \\
\text { Bijuterias }\end{array}$ & Baixa & baixa & baixa & Baixa & baixa & baixa & baixa & baixa & baixa & baixa \\
\hline \multirow{4}{*}{$\begin{array}{c}\text { Câmaras } \\
\text { Setoriais do } \\
\text { Agronegócio }\end{array}$} & Café & média-alta & média-alta & média & Média & média & média & média & alta & média-alta & média \\
\hline & Uva e Vinho & Baixa & média & baixa & Baixa & baixa & baixa & baixa & baixa & baixa & baixa \\
\hline & Turismo & Baixa & baixa & baixa & Baixa & baixa & baixa & baixa & baixa & média & baixa \\
\hline & Frutas & $\begin{array}{c}\text { média- } \\
\text { baixa }\end{array}$ & média & média & Média & média & média & baixa & média & média & baixa \\
\hline \multirow{2}{*}{$\begin{array}{l}\text { Circuito } \\
\text { Turístico }\end{array}$} & Frutas & média-alta & média-alta & alta & Alta & média-alta & média & média & média & média-alta & baixa \\
\hline & Águas & Média & média & média & Alta & média-alta & média & média & média & média & baixa \\
\hline $\begin{array}{l}\text { Comitê de } \\
\text { Bacia } \\
\text { Hidrográfica }\end{array}$ & $\begin{array}{l}\text { Piracicaba - Capivari - } \\
\text { Jundiaí }\end{array}$ & média-alta & alta & média-alta & média-alta & média-alta & média-alta & média & média & média & baixa \\
\hline
\end{tabular}

Fonte: Pires et al., 2013, p 11. 

A utilização de parâmetros qualitativos, que envolvem subjetividade, é justificável se adotarmos o ponto de vista proposto por Ginzburg (2006). "O fato de uma fonte não ser objetiva [...] não significa que seja inutilizável” (p. 16). O autor em questão conta a história de Menocchio - um moleiro, que foi queimado por ordem do Santo Ofício - a partir dos documentos dos processos que sofreu e de fragmentos de outros documentos que fornecem um quadro geral de sua vida (profissão, filhos, ideias) e permitem reconstuir um fragmento "do que se costuma denominar de 'cultura das classes subalternas' [...]" (p. 11).

Reconstrução baseada em fontes escritas 'duplamente indiretas por serem escritas e, em geral, de autoria de indivíduos, uns mais outros menos, abertamente ligados à cultura dominante. Isso significa que os pensamentos, crenças, esperanças dos camponeses e artesãos do passado chegam até nós através de filtros e intermediários que os deformam' (GINZBURG, 2006, p. 13).

Apesar da subjetividade das fontes, os indícios coletados ajudam a entender as ações do moleiro dentro daquele contexto histórico. De maneira parecida, a avaliação dos parâmetros qualitativos exposta no quadro 2 envolve a percepção subjetiva dos pesquisadores, formada através da análise dos dados secundários, das entrevistas e das discussões entre eles basaeadas nessas informações. O quadro 2 ajuda a explicar o funcionamento das estruturas de governança e fornece indícios, a partir da percepção dos pesquisadores, da pequena participação e da assimetria de informações que permitem afirmar que a cooperação não é efetiva no âmbito das estruturas de governança estudadas.

A pequena participação é evidenciada por três princípios. O primeiro deles é o "mecanismo", que trata da agenda coletiva de trabalho e da divisão de tarefas dos atores envolvidos, do cronograma de reuniões e das mesas de negociações. Dez estruturas são classificadas como "baixa" neste quesito, ou seja, não apresentam nenhum dos requistios listados logo acima.

O segundo princípio, "participação”, evidencia quais atores convidados estão inseridos de fato nas estruturas de governança. Doze das estruturas estudadas foram classificadas como "baixa" neste quesito. Nestas há atores convidados que não participam de fato do funcionamento da estrutura.

O terceiro princípio, "representatividade", verifica a participação de determinados grupos, tais como sindicatos, os não proprietários de terras ou de empresas e organizações associativas. Dez estruturas são classificadas como "baixa" neste quesito, ou seja, são pouco representativas.

No que diz respeito à participação, é preciso salientar que os atores com muitos recursos ou mais habilidosos no seu uso terão maior facilidade para impor suas ações aos demais atores. Por isso que alguns resultados são mais prováveis que outros dentro do jogo (MARQUES, 2006).

O grupo esperava que a desigualdade intrínseca ao jogo fosse amenizada dentro das estruturas de governança via participação já que elas são concebidas

[...] para ampliar os mecanismos de participação política e cidadã nos processos de tomada de decisão e de gestão da produção do espaço, e deveriam estar associados à legitimidade da representação e da 
organização de interesses de grupos e classes sociais locais e regionais (PIRES et al., 2012, p. 5).

Supostamente, as decisões tomadas nestes termos reforçariam os laços sociais de pertencimento e trariam um desenvolvimento mais adequado às aspirações regionais. No entanto, não é isto que acontece. Exceção feita ao comitê de Bacia dos Rios Piracicaba, Capivari e Jundiaí (PCJ) no qual

[...] a Governança é Pública-Tripartite, isto é, quando são as instituições públicas e as organizações privadas e da sociedade civil, que juntas impulsionam a coordenação compartilhada de recursos e estratégias territoriais nos projetos de desenvolvimento. Neste caso, através de Câmaras, Conselhos, Consórcios, Comitês, Agências ou Fóruns voltados à gestão das políticas públicas territoriais. São situações mistas e raras, de autonomia relativa e sem domínio unilateral ex-ante (PIRES et al., 2013, p. 6).

As demais estruturas identificadas pelo grupo - câmaras setoriais, circuitos turísticos, arranjos produtivos locais - são desprovidas de

[...] participação cidadã e de processos transparentes de decisões democráticas no uso dos recursos públicos. Esses novos arranjos seriam concebidos para ampliar os mecanismos de participação política e cidadã nos processos de tomada de decisão e de gestão da política pública, e deveriam estar associados à legitimidade da representação e da organização de interesses de grupos e classes sociais locais e regionais (PIRES et al., 2013, p. 5).

A redução das assimetrias de informação era outra consequência esperada do funcionamento das estruturas de governança. Para pensar e agir, um ator processa e produz informação sobre a situação na qual ele se encontra e sobre os demais atores (preferências, interesses, capacidade de manejo dos recursos, sua diposição em utilizar tais recursos, etc.). De acordo com Pozzi (1983), a situação estabelece o motivo, "o se ou o então" (p. 47) que impele o ator para ganhar o jogo, calculando suas ações racionalmente para o fim estabelecido, o que não significa a certeza do acerto.

A situação na qual o ator se encontra condiciona a sua avaliação dela, dos seus interesses e dos demais atores. Cada ator pensa e age em função da situação na qual se encontra envolvido, processando informação de maneira subjetiva. O resultado é a incerteza e a informação incompleta, já que o ator não consegue conhecer toda a sua situação e, muito menos, as motivações, interesses e possibilidades de ação dos demais atores (MATUS, 1996).

Vale repetir, recorrendo a North (1993) mais uma vez, que a motivação dos atores é complexa e suas preferências mudam ao longo do tempo. Caracterísiticas que os levam a escolher a partir de modelos derivados subjetivamente que não convergem e a processar a informação de maneira incompleta. Tais caracterísisticas têm um papel crítico na tomada de decisão e impõem a necessidade de criar "pautas regularizadoras" da interação entre atores.

O quadro 2 fornece indícios de que o funcionamento das estruturas de governança não reduziu as assimetrias de informação. Pelo contrário. Os princípios 
"transparência”, "accountability" e "coerência” fornenecem indícios que sustentam esta afirmação. O princípio "transparência" refere-se ao acesso do público e dos atores participantes às informações geradas no âmbito da estrutura. Neste quesito, onze das dezoito estruturas estudadas receberam a classificação "baixa" e apenas uma, a "alta". O pequeno grau de transparência das relações entre atores é percebido pelas ações erráticas direcionadas aos objetivos (PIRES et al., 2013).

O princípio da "accountability" enfatiza a disposição das lideranças em prestar contas e divulgar dados sobre as ações empreendidas ou não no âmbito da estrutura. Em onze estruturas, a classificação referente a este princípio foi "baixa". Nenhuma atigiu o quesito "alta" e apenas uma estrutura foi classificada como "média-alta", caracterizando a falta de clareza das funções e de responsabilidades dos atores envolvidos (PIRES et al., 2013).

O princípio da "coerência" diz respeito à capacidade dos atores partipantes em manter o foco e promover acordos em relação ao desenvolvimento local. Neste quesito, doze das estruturas identificadas foram classificadas como "baixa". Nenhuma estrutura foi classificada como "alta", indicando que a ausência de articulação entre as ações realizadas no âmbito das estruturas com as políticas públicas em vigor no estado e na União (PIRES et al., 2013).

\section{Dicussão dos resultados}

\subsection{Uma possível explicação a partir da matriz institucional brasileira ${ }^{6}$}

A montagem e o funcionamento das estruturas de governança no interior do estado de São Paulo são influenciados pela matriz institucional brasileira, o que explica, em grande medida, a pequena participação e as assimetrias de informação que dificultam os comportamentos cooperativos. Os resultados encontrados são indícios de comportamentos legítimos sancionados pela matriz institucional brasileira, baseada nos valores da família partriarcal.

Para Freyre (2003), a sociedade brasileira foi marcada pela colonização apoiada na inciativa particular, uma vez que não havia um "sistema regular e complexo de administração" (p. 80). A família foi o alicerce da "colonização particular" (p. 81) e não o indivíduo ou o Estado. Ela foi a força social que se desdobrou em política, caracterizada pelo nepotismo e pela oligarquia.

De acordo com Holanda (1995), as relações familiares são o molde das demais relações sociais e influenciam diretamente a formação e funcionamento da sociedade brasileira. Os valores da família patriarcal são expressos na cultura da personalidade, na qual "o valor de um homem infere-se, antes de tudo, da extensão em que não precise depender dos demais [...] " (p. 32). Tais valores favorecem a frouxidão da hierarquia social e a debilidade das formas de solidariedade e implicam na ausência de um acordo coletivo durável e na repulsa das atividades que necessitam do trabalho grupal.

Outra característica herdada do perío do colonial é a convivência de contrários que não entram em conflito, mas que se acomodam. O colonizador português, caracterizado pela mobilidade e miscibilidade, era rico em antagonismos:

\footnotetext{
${ }^{6}$ Esta seção é baseada em outros artigos sobre os resultados da pesquisa. Ver Figueiredo Filho (2012, 2015).
} 
europeu/africano, cristão/maometano, dinâmico/fatalista. Junto com o negro e o índio formou uma cultura marcada pelo encontro de tradições diversas, muitas delas antagônicas, que, no entanto, não geraram conflitos, mas acomodação (FREYRE, 2003)

Para Holanda (1995), a sociedade brasileira é caracterizada pela convivência de duas morais contrapostas, a do aventureiro e a do trabalhador, expressas na "ânsia por prosperidade sem custos [...] que se desencaminha antes de encontrar resistência [...]" (p. 46). A flexibilidade e a adaptabilidade, típicas da sociedade brasileira, são o resultado da convivência de contrários que não resulta em conflito, mas em acomodação e torna o brasileiro "livre para se abandonar a todo repertório de ideias, gestos e formas que encontra em seu caminho, assimilando-os frequentemente sem maiores dificuldades" (p. 151).

A noção de contrários que não entram em conflito, mas se acomodam e convivem também é utilizada por Oliveira (2003) para explicar a persistência da convivência do arcaico com o novo. O populismo, expressão desta convivência, é fruto da falta de uma autêntica revolução burguesa. Por isso, o autor em questão descreve o Brasil através da imagem do ornitorrinco. Animal que combina características dos anfíbios e mamíferos. Da mesma maneira, o Brasil combina práticas modernas e atrasadas através de um processo de modernização conservadora, ou seja, uma revolução produtiva sem uma revolução burguesa de fato.

Holanda (1995) sintetiza a convivência do novo com o arcaico ao explicar que o fim da escravidão não levou a alterações significativas no funcionamento da sociedade brasileira. Pergunta, então: "como esperar transformações profundas de um país onde eram mantidos os fundamentos tradicionais da situação que se pretende ultrapassar?" (p. 78).

Os valores da família patriarcal e a convivência de comportamentos opostos permitem que práticas oligárquicas e patrimonialistas, embora ilegais, convivam com as regras burocráticas e impessoais que regem o funcionamento de um Estado de direito democrático. Expressão desta situação é a distinção, comum por aqui, entre as leis que pegam e as leis que não pegam. Para DaMatta (2006), estas últimas são aquelas "que a própria sociedade almeja e diz que quer, mas que, por contrariarem práticas sociais bem estabelecidas, 'não pegam', como, por exemplo, as que mandam ocupar cargos públicos somente por concurso" (p. 266).

Os valores da família partiarcal e a convivência de contrários que não entram em conflito ajudam a explicar a pequena participação e as assimetrias de informação encontradas nas estruturas de governança estudadas. A falta de agenda, de rodízio de poder, de divulgação de informações que permitem a cobrança, avaliação e igualdade de participação, e a ausência de mecanismos de decisão são indícios de que aqueles valores, ainda hoje, são legítimos e servem de guia para pensar e agir.

Tais valores são heranças culturais da sociedade que ligam o passado ao presente através da inércia institucional, dado que o "sistema institucional não tem a propriedade da auto-correção" (MARTONE, 2007, p. 6). No entanto, vale lembrar Douglas (1998) mais uma vez: as instituições mudam na medida em que perdem ou ganham legitimidade já que a trajetória de uma sociedade não é pré-determinada. 
Os resultados autorizam o pessimismo, mas também indicam o inicío de uma mudança muito lenta que poderá acarretar uma modificação institucional no futuro, já que não estamos presos indefinidadamente nesta situação.

\subsection{0 "pessimismo lúcido"}

A situação encontrada é ruim. Mas é melhor estruturas de governança funcionando precariamente do que nenhuma. Por isso, o "pessimismo lúcido". A expressão é do autor do prefácio de "Partidos Políticos" de Robert Michels (1982), que classifica as conclusões de Michels de pessimistas e, ao mesmo tempo, lúcidas. A tese central da obra diz que todo partido político, inclusive os revolucionários, têm tendências oligárquicas. "Qualquer órgão da coletividade, nascido da divisão do trabalho cria, para si, logo que estiver consolidado, um interesse de si e para si" (p. 234). Tendências que derivam da necessidade de ordem social e estão presentes em qualquer regime político.

Nos regimes democráticos, as tendências oligárquicas se manifestariam pelas disputas entre minorias que resultariam em novas oligarquias unidas às antigas. São estas disputas que abririam pequenos espaços para a participação e renovação. Situação longe da ideal, mas que permitiria pequenos e lentos avanços ao longo do tempo. Por este motivo o "pessimismo lúcido", porque dele não resulta o desespero.

Para North (1993), os regimes democráticos são caracterizados pela dificuldade da maioria, isto é, os vários grupos de interesses políticos e econômicos não conseguem formar maioria para que seus interesses prevaleçam. São obrigados a estabelecer acordos, inclusive os governos. Nesta situação, os compromissos estabelecidos e o seu autocumprimento são a base da cooperação e da redução da incerteza. Os regimes democráticos geram várias possibilidades de acordo e, neste sentido, são eficientes, porque a maior participação limita a ação "caprichosa" do governante.

Neste mesmo sentido, Santos (2004) explica as diferenças de desenvolvimento entre o sul e o norte italianos a partir da ideia de que sistemas políticos poliarquicos são mais eficazes para o desenvolvimento. A participação serve como freio para as ações dos governantes, limitando seu poder ou os obrigando a negociar.

Historicamente, a formação das "cidades-repúblicas", no norte da Itália, impõe limites aos governantes através da participação. Esta característica se adpata melhor aos regimes democráticos atuais nos quais a competição pelo poder acontece dentro de certas regras. Em contrapartida, o sul italiano é caracterizado "pela lógica da exploração colonial” (p. 149), na qual os governantes não encontram limites dados pela participação de outros atores.

Para Evans (2003), a participação tem impacto positivo no desenvolvimento de um país ou região. A existência de mecanismos que incentivem a participação proporciona o debate de alternativas, a participação em processos deliberativos e "são complementos essenciais da governança que tornam eficazes capital e tecnologias" (p. 22).

Maior participação implica que as relações entre atores podem ser descritas através de inúmeros acordos formais e informais que são constantemente 
renovados, revistos e revogados a partir da criação e transmissão das informações disponíveis. Ao produzirem e utilizarem informação, os atores tornam a estrutura social mais fluída e "aumenta a série de comportamentos alternativos franqueados aos componentes" (BUCKLEY, 1971, p. 76).

Entretanto, os fluxos de informações interligam assimetricamente os diferentes atores que escolhem e decidem a partir de modelos subjetivos da realidade que não convergem e da sua limitada capacidade de processamento de informação (NORTH, 1993).

Para Buckley (1971), as informações podem ser divididas em três tipos: a do mundo exterior, do passado e acerca de si mesmo. Cada tipo de informação tem especificidades, mas todos eles permitem o aprendizado e a adaptação às novas circunstâncias, o que gera tensão que decorre da resposta a estímulos contraditórios. Por um lado, a própria sociedade demanda esforço para a manutenção das estruturas criadas. Por outro lado, a mesma sociedade demanda novas estruturas que a ajudem na adaptação às novas situações. "O modelo sócio-cultural é elaborador e modificador de estruturas [...] que mudam continuamente suas estruturas como adaptações às condições internas ou externas" (BUCKLEY, 1971, p. 37).

As estruturas de governança podem ser descritas da mesma maneira da proposta de Buckley. Representam uma resposta a uma nova situação posta pela busca do desenvolvimento sustentável. Desempenhariam esta tarefa incentivando a maior participação para gerar maior variedade de possibilidades de soluções, reduzindo comportamentos oportunistas e assimetrias de informação de maneira a tornar menos desproporcional o acesso dos atores ao processo de decisão para enfrentar os problemas postos por aquela busca.

No entanto, as estruturas de governança identificadas que funcionam no interior do estado de São Paulo não garantem a participação efetiva e a redução das assimetrias de informação. Podem, então, ser descritas como pequenos e imperfeitos espaços de participação e cooperação para a promoção do desenvolvimento territorial.

\section{Considerações finais}

O artigo propõe uma discussão do resultado geral da pesquisa em questão - a fragilidade da cooperação no âmbito das estruturas estudadas - a partir de um modelo formado por dois conceitos: atores e instituições. O primeiro diz respeito a grupos humanos formados por objetivos comuns que pensam e agem com vistas a um objetivo. São estratégicos porque levam em consideração as prováveis ações e reações dos demais jogadores. As instituições dizem respeito às regras legítimas, formais e informais, que conformam preferências e estratégias dos atores, limitando suas escolhas. Neste sentido, reduzem a incerteza.

Em âmbito regional, os atores não têm os recursos necessários para influenciar decisivamente nos rumos do desenvolvimento, ainda mais se considerarmos a noção de sustentabilidade que expõe os mais variados interesses. Por isso, há demanda por mecanismos que facilitem a construção de consensos e o encaminhamento de conflitos. As estruturas de governança representam um destes instrumentos. Fornecem parâmetros para que os atores cooperem através do encaminhamento dos conflitos que surgem da divergência de interesses envolvidos 
na busca pelo desenvolvimento sustentável regional, via participação e redução das assimetrias de informação.

No entanto, o trabalho de campo evidenciou que as estruturas de governança não cumprem bem as tarefas de incentivar a participação e reduzir as assimetrias de informação. A cooperação é bastante limitada e não há lideranças legítimas para mediar os conflitos que surgem dos difrentes interesses e objetivos. O funcionamento das estruturas de governança identificadas contrubui pouco para o desenvolvimento sustentável regional.

Uma possível explicação para os resultados do trabalho de campo é dada pela matriz institucional brasileira que legitima comportamentos que inibem a cooperação e a construção de acordos duráveis entre os atores participantes das estruturas de governança. Entrentanto, isto não significa que tal situação perdurará indefinidamente. As instituições não têm a propriedade da autocorreção, mas, na medida em que perdem ou ganham legitimidade, podem mudar o curso de ação dos atores no futuro.

Apesar da falta de agenda, de rodízio de poder, da ausência de mecanismos de decisão e da dificuldade de divulgar informações que resultam na participação truncada e na persistência das assimetrias de informação, as estruturas de governança ainda podem ser descritas como um pequeno passo pela busca de um desenvolvimento regional mais justo e equilibrado. Apesar do pessimismo permitido pelos resultados encontrados, elas ainda podem ser descritas como uma pequena abertura para uma mudança institucional que é lenta.

\section{REFERÊNCIAS}

ARON, R. Introdução: os níveis conceituais de compreensão. In: . Paze

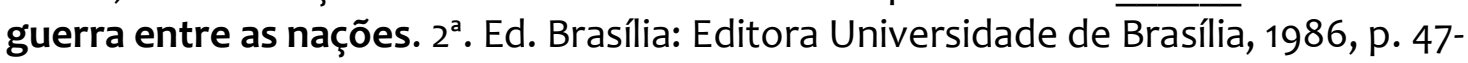
68.

BECK, U. Liberdade ou capitalismo: Ulrich Beck conversa com Johannes Willms. São Paulo: Editora UNESP, 2003.

BUCKLEY, W. A sociologia e a moderna teoria dos sistemas. São Paulo: Cultrix; Editora da USP, 1971.

DE BRUYNE, P.; HERMAN, J.; SCHOUTHEETE, M. Dinâmica da pesquisa em ciências sociais. $5^{\text {a }}$. Ed. Rio de Janeiro: Livraria Francisco Alves Editora, 1997.

DAMATA, R. 2006 Desafios do milênio: o papel e a razão da sociedade. In: OLIVA, A. et al. $O$ dever do Estado. Porto Alegre: IEE, 2006, p. 263 - 274.

DOUGLAS, M. Como as instituições pensam. São Paulo: Editora Universidade de São Paulo, 1998.

EVANS, P. “Além da monocultura institucional”: instituições, capacidades e o desenvolvimento deliberativo. Sociologias, no. 9, p. 20-63, jan/jun 2003. 
FIGUEIREDO FILHO, W.B. Estruturas de governança regionais, desenvolvimento sustentável e legitimidade: notas para a construção de um esquema de referência. Revista de desenvolvimento econômico, n. 26, p. 136-144, dez. 2012. Disponível em: <http://www.revistas.unifacs.br/index.php/rde/article/view/2299/1782>. Acesso em: dez. 2012.

FIGUEIREDO FILHO, W.B. Estruturas de governança, cooperação e legitimidade na construção do desenvolvimento regional no interior do estado de São Paulo:

algumas notas preliminares. Redes, Santa Cuz do Sul, v. 20, no. 1, p. 52-68, jan./abr. 2015. Disponível em:

<http://online.unisc.br/seer/index.php/redes/article/view/4133/pdf18>. Acesso: abr. 2015.

FREYRE, G. Casa Grande \& Senzala: formação da família brasileira sob o regime da economia patriarcal. 48 Ed. São Paulo: Globo, 2003.

GINZBURG, C. O queijo e os vermes: o cotidiano e as ideias de um moleiro perseguido pela Inquisição. São Paulo: Cia das Letras, 2006.

HALL, P.A., TAYLOR, R.C.R. As três versões do neo-institucionalismo. Lua Nova, n. 58, p. 193-223, 2003. Disponível em: <http://www.scielo.br/pdf/In/n58/a10n58.pdf>. Acesso em: jan. 2013.

HOLANDA, S.B. Raízes do Brasil. 26ª Ed. São Paulo: Cia das Letras, 1995. LESSA, C. A. Racionalidade estratégica e instituições. Revista Brasileira de Ciências Sociais, v.13, no. 37, p. 129-148, jun.1998.

MARQUES, E.C. Redes sociais e poder no Estado brasileiro. Aprendizado a partir das políticas urbanas. RBCS, $n^{\circ} .60$, p. 15-41, fev. 2006.

MARTONE, C.L. Instituições, Setor Público e Desenvolvimento: O Caso do Brasil. Texto para discussão FIPE, no. 9, 2007. Disponível em: <http://www.fipe.org.br/Content/downloads/publicacoes/textos/texto_09_2007.pdf >. Acesso em: dez. 2012.

MATUS, C. Adeus, senhor Presidente. Governantes governados. São Paulo: Edições FUNDAP, 1996.

MICHLES, R. Sociologia dos partidos políticos. Brasília: Editora da Universidade de Brasília, 1982.

NORTH, D. C. Instituciones, cambio institucional y desempeño econômico. México D.F.: Fondo de Cultura Econômica, 1993.

OLIVEIRA, F de. Crítica à razão dualista/O ornitorrinco. São Paulo: Boitempo, 2003. PIRES, E (coord.); FUINI, L.L.; MANCINI, R.F.; OTANI, M; SOUZA, M.C.; STAUD, N.; VERDI, A.R. As modalidades de governança territorial no Estado de Estado de São Paulo: projeto de pesquisa. Rio Claro: UNESP, 2011. 
Estruturas de governança no interior do estado de São Paulo: participação truncada e assimetrias de informação

PIRES, E. (coord.); FIGUEIREDO FILHO, W.B.; FUINI, L.L.; MANCINI, R.F.; OTANI, M; SOUZA, M.C.; STAUD, N.; VERDI, A.R. As modalidades de governança territorial no Estado de Estado de São Paulo: relatório de pesquisa. Rio Claro: UNESP, 2012.

PIRES, E. (coord.); FIGUEIREDO FILHO, W.B.; FUINI, L.L.; MANCINI, R.F.; OTANI, M; SOUZA, M.C.; STAUD, N.; VERDI, A.R. As modalidades de governança territorial no Estado de Estado de São Paulo: relatório final de pesquisa. Rio Claro: UNESP, 2013.

POZZI, E. Giochi di guerra e tempi de pace. I war games nell'archeologia del sapere. La critica sociológica, no. 67, p. 42 55, set/out de 1983. Disponível em:

<http://www.enricopozzi.eu/pubblicazioni/Lo\%20sport\%20tra\%20natura\%20e\%20cultu ra/giochi.guerra.pdf>. Acesso em: abr. 2011.

SANTOS, A. M. Democracia e valores cívicos: uma relação necessária? São Paulo, Novos Estudos CEBRAP, no. 69, p. 145 -160, julho de 2004.

SILVA, B. (coord.). Dicionário de Ciências Sociais. Rio de Janeiro: Editora da Fundação Getúlio Vargas, 1987.

Wilson Bento Figueiredo Filho. Professor da Academia da Força Aérea (AFA). wfigueirdo11@gmail.com

Como citar: FIGUEIREDO FILHO, Wilson Bento. Estruturas de governança no interior do estado de São Paulo: participação truncada e assimetrias de informação. Redes, Santa Cruz do Sul, v. 24, n. 1 p. 356-374, jan. 2019. ISSN 1982-6745. Disponível em: https://doi.org/10.17058/redes.v24i1.6524. 